\title{
ASPECTS OF USING 3-D LASER SCANNING TECHNOLOGY IN SHIP RETROFIT PROJECTS
}

\author{
Vasile Rață \\ ICEPRONAV ENGINEERING SRL \\ Portului Street, No 19A \\ Galati, Romania \\ E-mail:vasile.rata@icepronav.ro
}

\author{
Steluta Secobeanu \\ ICEPRONAV ENGINEERING SRL \\ Portului Street, No 19A \\ Galati, Romania \\ E-mail:steluta.secobeanu@icepronav.ro
}

\begin{abstract}
The number of ship retrofit and conversion projects has increased dramatically over the last couple of years, mainly as a result of new international regulations to limit environment pollution. Another driver has been conversion of oil tankers into floating production, storage and offloading (FPSO) vessels as offshore oil and gas production has moved into deeper waters. The need to accurately establish the existing location of equipment and systems onboard ships prior to a retrofit project has lead to an increasing use of 3-D laser scanning. This technology brings benefits as it increases the accuracy of the retrofit design and associated production information and it shortens the time needed for the onboard survey. The paper describes the laser 3-D technology and compares the time allocated to the classical practice of collecting input data onboard of ships with 3-D laser scanning activity, based on review of records from several onboard scanning and subsequent retrofit projects.
\end{abstract}

Keywords: 3-D laser scanning, as-built data, retrofit project, ship retrofit

\section{INTRODUCTION}

An increased awareness of the harmful effect ships have on the environment has resulted in the International Maritime Organisation (IMO), a regulatory body under the United Nations, issuing regulations that require ships to limit certain emissions to the air and sea. In addition, a set of recent national regulations aiming at protecting air quality apply to shipping in certain geographical zones. Together, these regulations create the need to upgrade a large part of the existing fleet since it is not economically feasible to fully replace it. The BWM Convention and MEPC 70 can be mentioned as an example of regulations that in many cases require installation of new equipment and systems.

The BWM Convention was adopted on 13 February 2004 and it entered into force on 8 September 2017 [1]. MEPC 70 was adopted on October 2016, and shall become effective on 1 January 2020. These regulations give rise to a series of modernization projects for ships with Ballast Water Treatment [2], Scrubber, HFO Fuel to MDO/MGO Fuel system adaptation, etc. [3],[4].

At the same time that the abovementioned amount of retrofit projects take place, there is renewed interest in converting existing oil tankers into oil storage and processing units [5], which draws on some of the same ship retrofit resources. 
Modification of existing ships requires gathering a large amount of input data to establish the actual location of existing equipment and systems, which often is different from what is shown on drawings from when the ship was built. In the past, the onboard survey procedure involved taking photographs and measurements to update "asbuilt" drawings in all arease likely to be affected by new installations, for use to design the conversions with the minimum of impact on the existing ship and thus the lowest possible cost.

Today, the classical process of data acquisition is increasingly replaced by using 3D laser scanning technology in the areas of interest, generating input data called "point clouds".

\section{3-D Laser scanning technology}

The technology behind the 3-D scanning process appeared around the 1960s [6]. The devices intended for the scanning process used light initially, only after 1985 was laser light was adopted. The laser light can be visible or invisible. When the light with which the 3-D laser scanning devices work is not perceived by the human eye, the beams are part of the infrared spectrum. The technology has evolved over the past decades, so today there are a number of devices and software solutions on the market dedicated to "as-is" data collection and subsequent processing.

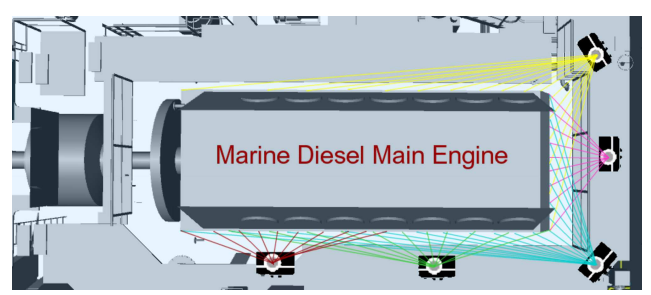

Fig.1. Object-oriented scanning

Basically, this technology is oriented to physical objects, see the approach from Fig. 1 , which are in the field of vision of the scanning device in order to scan the object by creating a field of close points produced by the laser beam emitted by the device. The position of each point in the threedimensional space is determined by measuring the response time of the laser beam leaving the scanning device to the scanned object, and then returning to the scanning device. As a result of this scanning process, a "point cloud" results, which renders with high accuracy the physical object scanned from a dimensional point of view in a digitized format. The "point cloud" containing "as is" information for a single scan can consist of several thousand points to tens of millions of individual points, each point having its own information in a three-dimensional coordinate system [7].

The scanning device is working by sending an infrared laser fascicle in the center of the rotating mirror, like in Fig. 2, which will hit the physical object and it is returning to the mirror's scanner, being reflected.

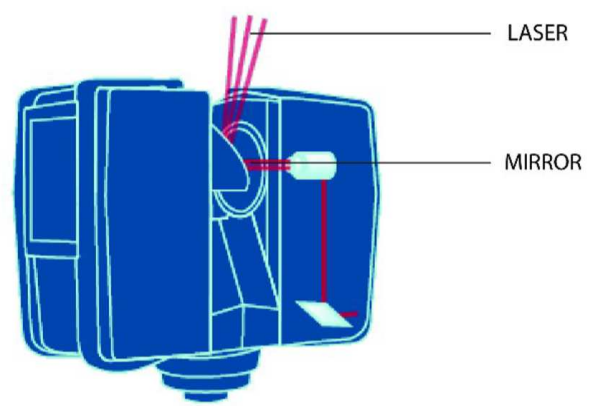

Fig.2. Scanner's laser fascicle principle [8]

The mirror deflects the laser fascicle, due to 360-degree angle moving of the entire device in the horizontal plane and 300-degree angle of the mirror moving around its own axis, as is presented in Fig. 3.

The distance between the solid object and the 3-D scanning equipment is determined using the phase shift technology of the infrared light waves. 

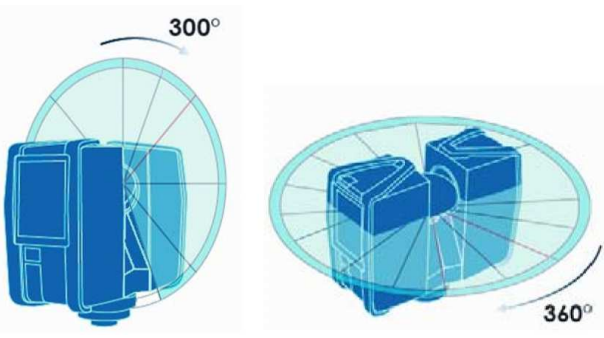

Fig.3. Scanner's mirror principle [8]

\section{CASE STUDY}

The process of scanning for engineering purposes is already used on a quite large scale, by companies world-wide. 3-D laser scanning is already a common technique for modernization, repair and conversion activities in the shipbuilding industry [9].

In the case of naval retrofit projects, the main challenge is to find suitable space in order to accommodate the new equipment, structure and systems, often needing a lot of space.

The digital environment obtained after post-processing a number of laser scans, depending on the size of the project, looks like in Fig.4. The total number of scans varies depending on the project requirements and represents a compromise between the desire to gather as much information as possible and the limitations imposed by: costs, access on board, delivery date, etc.

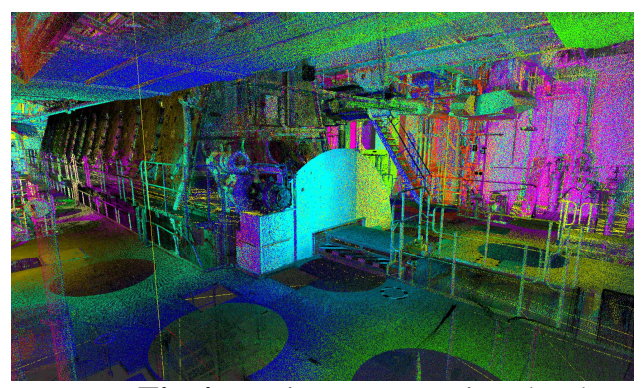

Fig.4. Engine Room point cloud

Fig. 5 shows comparable costs of a series of retrofit projects carried out by our company. The processes related to the survey, both classic and with the help of 3-D laser scanning techniques are: Preparing, Survey, Survey Data Processing, Retrofit Design Work, Retrofit Work, Cost of Retrofit Materials.

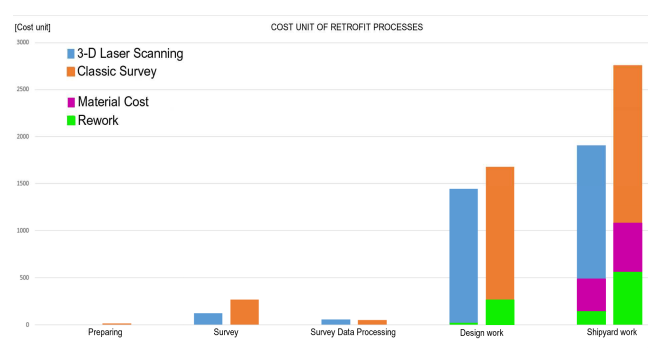

Fig.5. Relative Cost of Retrofit Processes

It is our experience that considerable reductions in both cost and time can be achieved by using point clouds compared to classical input for the subsequent design in the case of retrofit projects.

Our experience shows a difference of up to $22 \%$ in cost reductions, in the case of using 3-D laser scanning.

The cost related to the processes mentioned in Fig. 5 are represented in Fig. 6 in the case of a classic survey.

The percent of classic survey project represents $28 \%$ of Total Labour Work for the processes mentioned above.

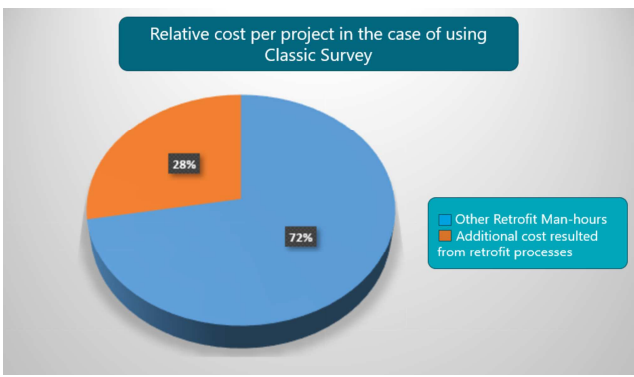

Fig.6. Additional cost for project in the case of using Classic Survey as a percentage of total retrofit man-hours

In case of 3-D laser scanning survey the percent for processes presented in Fig. 5 is 
9\% of Total Labour Work calculated for this approach, Fig.7.

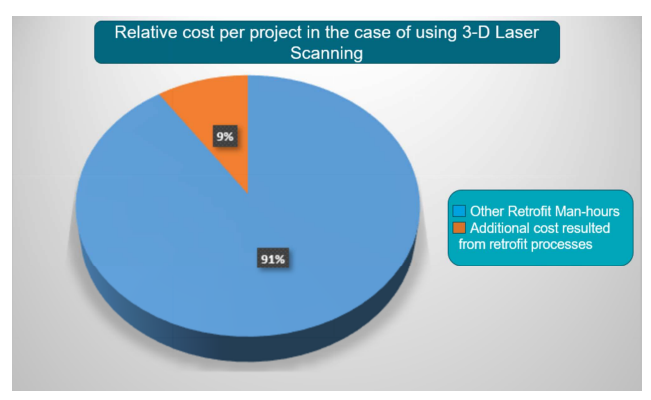

Fig.7. Additional cost for project in the case of using 3-D Laser Scanning as a percentage of total retrofit man-hours

As can be seen from Figures 6 and 7 above, using laser scanning can significantly reduce the survey effort as a portion of the overall man-hours involved in a retrofit project, thus reducing the overall cost.

\section{RESULTS AND DISCUSSIONS}

ICE is using Faro scanning technology for its projects, see fig. 8 .

The use of the 3-D laser scanning solution has proved to be a viable solution and has been adopted in the naval industry in the case of retrofit projects and sometimes in the case of conversion projects.

Unfortunately, 3-D laser scanning is not commonly used in new ship construction, probably because decision makers are not well informed about the capabilities of the information resulting from such processes.

Another consideration would be the additional cost; however, this cost comes with benefits such as:

$>$ Use the point cloud as a tool to check the quality of the works delivered by the shipyard.

$>$ Use of the point cloud as evidence in the event of incidents occurring during the warranty period.
$>$ Use of point cloud for easier maintenance, including installation of systems / systems on board the ship in later stage.

$>$ Use of the information from the point cloud and of the photos to perform a 360 degree virtual tour onboard.

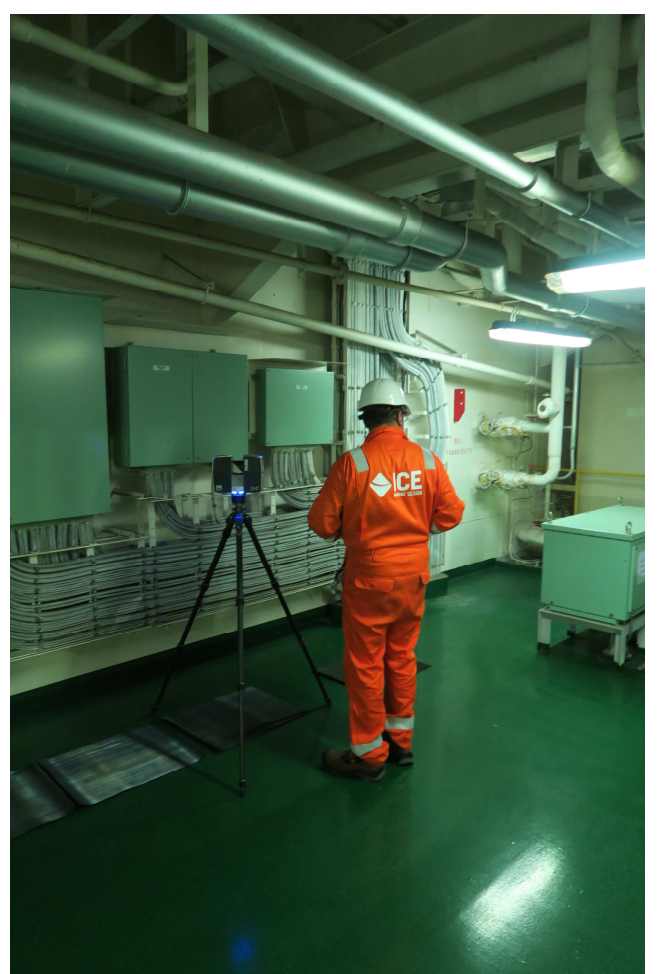

Fig.8. ICE's surveyor/scanner

\section{Weak points}

- Some laser systems are not intended for use in sun or rain.

- Accuracy of the data points is not perfect regarding the spatial positioning of all scans (in a large project) in relation to a given / chosen UCS.

- Big data set of 3-D information requires considerable time and resources to process and postprocess. 
- To make the information readyto-use requires numerous manual actions of the user.

- There may be problems when representing the edges from two or more different scans.

- The difficulty to keep up to date with the latest improvements and developments, both software and hardware.

- Requires dedicated software due to the format in which the data is saved.

- Expensive software applications and scanning devices.

\section{Strong points}

- Fast 3-D data collection process.

- Very useful for 3-D modeling, data inputs and visualization purpose.

- Possibility to use 360 degree photography as "bubble views".

- 3-D but also 2-D applicability for surfaces.

- Efficiency in terms of the large volume of information collected to a predictable accuracy.

- Extensive technology development due to research and development projects worldwide [10].

\section{CONCLUDING REMARKS}

Reverse engineering [11] combined with the benefits of 3-D laser scanning technology and post processing is ideal for processes like redesign, control and measurement, retrofitting of existing systems or structures in the shipbuilding industry [12].

Taking into account the experience gained in more than several dozen scanning projects, we can say that laser scanning technology added value in the projects in which it was used as well as in a large number of en- gineering projects in which "point clouds" data were used. We can recall several major ship conversion and modernization projects carried out years ago where we believe that this innovative technology could have streamlined the survey and modeling processes of existing information.

The assuming and use of new technologies in a proactive attitude leads, on a shortterm basis, to the efficiency of some old processes and improvement of procedural issues. This will ultimately lead to the client's satisfaction.

\begin{abstract}
About us
Icepronav Engineering is part of the International Contract Engineering (ICE) group, the Europe's largest independent ship design consultancy. It is an amalgamation of a longstanding U.K. provider of marine design services and a former Romanian state-owned ship research institute established over 50 years ago. ICE has successfully performed dozens of retrofit projects and a series of conversions or major upgrades of vessels, from different fields: commercial, offshore, naval, etc. (www.icedesign.info)
\end{abstract}

\section{ABBREVIATIONS}

2-D - TWO-DIMENSIONAL

3-D - THREE-DIMENSIONAL

IMO - INTERNATIONAL MARITIME

ORGANISATION

FPSO - FLOATING PRODUCTION

STORAGE AND OFFLOADING

BWM - BALLAST WATER MANAGE-

MENT

MEPC - MARINE ENVIRONMENT PRO-

TECTION COMMITTEE

UCS - USER COORDINATES SYSTEM

\section{Acknowledgements}

The authors express great thanks for the support from project ANTREPRENORDOC within the framework of Human Resources 
Development Operational Program 20142020, financed from the European Social Fund under the contract number 36355/23.05.2019 HRDOP/380/6/13-SMIS Code: 123847.

\section{REFERENCES}

[1]. International Maritime Organisation, accessed in September 2019: www.imo.org/ en/MediaCentre/PressBriefings/Pages/21BWM-EIF.aspx

[2]. Rata, V. et. all, "Ballast Water Management in the Black Sea's Ports", J. Mar. Sci. Eng. 2018, 6(2), 69; https://doi.org/ 10.3390/jmse6020069, 2018.

[3]. "The Alfa Laval Adaptive Fuel Line Bluebook", Technical reference booklet -2018 Edition, accessed in September 2019: www.alfalaval.com/globalassets/documents/ industries/marine-and-transportation/marine/ refuel/Bluebook_en.pdf

[4]. "2012 GUIDELINES FOR THE DEVELOPMENT OF A SHIP ENERGY EFFICIENCY MANAGEMENT PLAN”, Rresolution MEPC.213(63), March 2012.

[5]. Offshore oil production shows signs of turnaround, Chron, accessed in October 2019 https://www.chron.com/business/energy/arti cle/Offshore-oil-production-shows-signs-ofturnaround-13206190.php

[6]. Mostafa A.-B. E., "3D LASER SCANNERS: HISTORY, APPLICATIONS, AND FUTURE
“, DOI: 10.13140/2.1.3331.3284, 2011. Accesed in October 2019: researchgate.coml

[7]. Chao W., Yong K. C., "Application of Asbuilt Data in Building Retrofit Decision Making Process", International Conference on Sustainable Design, Engineering and Construction, Procedia Engineering 118 ( 2015 ) $902-908$.

[8]. FARO Laser Scanner Focus 3D X130 User Manual, March 2016.

[9]. Schoustra R.-J., Qualty made to fit, The naval Architect, October 2019.

[10]. Arayici Y., "An Approach for Real World Data Modelling with the $3 D$ Terrestrial Laser Scanner for Built Environment”, Automation in Construction, DOI: 10.1016/j.autcon. 2007.02.008, September 2007.

[11]. TASSETT A. N. et. all, "REVERSE ENGINEERING TECHNIQUES FOR TRAWLER HULL 3D MODELLING AND ENERGY EFFICIENCY EVALUATION", 18th International Conference on Ships and Shipping Research 2015, June 24th - 26th, Lecco, Italy.

[12]. Deja M. et. all, "APPLICATION OF REVERSE ENGINEERING TECHNOLOGY IN PART DESIGN FOR SHIPBUILDING INDUSTRY", POLISH MARITIME RESEARCH 2 (102) 2019 Vol. 26; pp. 126-133 10.2478/pomr-2019-0032.

Paper received on November $11^{\text {th }}, 2019$ 